\title{
Modelo espacio-temporal y red neuronal de Kohonen en la estimación del Producto Interno Bruto, Exportaciones e Importaciones post Covid-19
}

\author{
Josefrank Pernalete Lugo \\ josefrankpl@gmail.com \\ Ingeniero Químico y Msc en Matemática Aplicada \\ Universidad Nacional Experimental Francisco de Miranda \\ https://orcid.org/0000-0002-6625-1334 \\ Ysaelen Odor Rossel \\ odorysa@gmail.com \\ Ingeniero Industrial y Msc en Ingeniería Industrial \\ Universidad Nacional Experimental Francisco de Miranda \\ https://orcid.org/0000-0003-3160-3106
}

\section{RESUMEN}

La propuesta de un modelo espacio-temporal y red neuronal artificial Kohonen de mapas autoorganizados para la investigación documental y descriptiva, pronostica el volumen monetario ARIMA del Producto Interno Bruto, Exportaciones e Importaciones para el período 2020-2022 en millones de soles 94,540; 21,184 y 24,827. Evidenciando el error porcentual absoluto MAPE en 4,22\%; 7,45\% y 5,54\% para diciembre de 2022, en ajuste significativo a la base de datos 2007-2020 del Instituto Nacional de Estadística e Información INEI. El algoritmo de Kohonen, utilizó el aprendizaje no supervisado de tipo competitivo y se entrenó de tal forma que, en millones de soles por 20,000 unidades de incremento en el Producto Interno Bruto, las Exportaciones e Importaciones varían a 4,000 y 6,000 unidades.

Palabras Clave: algoritmo; aprendizaje; mapa autoorganizado; producto interno bruto; volumen monetario 


\title{
Kohonen's spatial-temporal model and neural network in the estimation of Gross Domestic Product, Exports and Imports
}

\begin{abstract}
The proposal of a spatial-temporal model and Kohonen artificial neural network of selforganized maps for documentary and descriptive research, predicts the ARIMA monetary volume of Gross Domestic Product, Exports and Imports for the period 2020-2022 in millions of soles 94,540;21,184 and 24,827. Evidence of the absolute percentage error MAPE in $4.22 \% ; 7.45 \%$ and $5.54 \%$ for December 2022, in significant adjustment to the 2007-2020 database of the National Institute of Statistics and Information INEI. Kohonen's algorithm used unsupervised competitive learning and was trained in such a way that, in millions of soles per 20,000 units of increase in the Gross Domestic Product, Exports and Imports vary between 4,000 and 6,000 units.
\end{abstract}

Keywords: algorithm; learning; self-organizing map; gross domestic product; monetary volume

Artículo recibido: 27 marzo 2021 Aceptado para publicación: 30 abril 2021 Correspondencia: josefrankpl@gmail.com Conflictos de Interés: Ninguna que declarar 


\section{INTRODUCCIÓN}

Las cuentas nacionales trimestrales, como parte exhaustiva del sistema de cuentas nacionales, constituyen un conjunto afín de transacciones, balances y saldos contables, definidos tanto en el sistema financiero como no financiero, registrados sobre una base trimestral, acogiendo los mismos elementos, enunciaciones y colocaciones de las cuentas nacionales anuales (Instituto Nacional de Estadística e Información , 2019). El método de cuentas nacionales trimestrales, se estipula en estimar en el corto plazo, los cambios macroeconómicos de la economía (INEI, 2020). El análisis predictivo del sistema de cuentas nacionales trimestrales involucra la modelización de series temporales, inteligencia artificial y minería de datos que analiza la evolución histórica de estos datos e infiere la tendencia actual y futura (International Finance Corporation, 2017).

En el presente año, el Instituto Nacional de Estadística e Información INEI en la República del Perú, promueve el desarrollo investigaciones orientada a temas relevantes como el impacto del COVID-19 en la economía del colectivo peruano, manipulando la información disponible de la base de datos derivada de las indagaciones estadísticas ejecutadas por el INEI (INEI, 2020). A su vez, con la producción del nuevo año fiscal base de las cuentas nacionales, el Perú se apegará en adaptar a las recomendaciones de la Organización de las Naciones Unidas y la Organización para la Cooperación y el Desarrollo Económico de calcular el Producto Interno Bruto constante utilizando la metodología de la Base Móvil y Encadenamiento, tomando como punto de partida los gráficos, mapas y comparaciones de más de 1000 indicadores de series de tiempo de los Indicadores de Desarrollo Mundial. (The World Bank, 2020).

En el estudio del Producto Interno Bruto Trimestral 2007-2020, con valores a precios constantes de 2007 y proyección al año 2022 para la República del Perú, el objetivo de la investigación es: proponer un modelo espacio-temporal y red neuronal artificial Kohonen de mapas autoorganizados en la estimación del Producto Interno Bruto, Exportaciones e Importaciones. Se trata de una investigación de tipo documental y descriptiva, ya que se ubicaron los datos consultando diferentes tipos de documentación histórica del Instituto Nacional de Estadística e Información del Perú INEI (Horna, 2020).

El artículo de investigación se desglosa en el desarrollo de la metodología de investigación y procesamiento de los datos; seguidamente se da escritura matemática al modelo de media móvil integrada autorregresiva, el pronóstico del error de la técnica y el 
algoritmo de aprendizaje de la red de inteligencia artificial. Posteriormente se presenta la tabla de recolección de los datos históricos del Producto Interno Bruto, Exportaciones e Importaciones 2007-2020, explicando los resultados más significativos en sinergia con la fiabilidad de cada modelo y pronóstico de los indicadores macroeconómicos, finalizando con las conclusiones representativas de la investigación y el sustento teórico a través de las referencias bibliográficas.

\section{METODOLOGÍA}

Se trata de una investigación de tipo documental y descriptiva, ya que se ubicaron los datos consultando diferentes tipos de documentación histórica del Instituto nacional de Estadística e Información del Perú, en el periodo 2007-2020 y proyectada para el año 2022 (Gauchi, 2017). Para el procesamiento de los datos se utilizó el modelo de series temporales ARIMA, el error porcentual absoluto medio de pronóstico MAPE y red neuronal artificial Kohonen SOM basado en código R (Ceballos \& Rodríguez, 2020). La hipótesis de investigación es: El análisis predictivo del modelo espacio-temporal y red neuronal de Kohonen para la estimación del Producto Interno Bruto, Exportaciones e Importaciones es significativo con un error porcentual absoluto medio MAPE menor o igual 10.

\section{Modelos ARIMA (r, k, s)}

El modelo de media móvil integrada autorregresiva ARIMA, es una combinación del modelo autorregresivo diferenciado con el modelo de media móvil y manifiesta la posibilidad de permutaciones estructurales a lo largo del tiempo (Song \& Park, 2019). Se expresa como:

$y_{t}^{\prime}=\sigma_{1} y_{t-1}^{\prime}+\sigma_{2} y_{t-2}^{\prime}+\cdots+\sigma_{r} y_{t-r}^{\prime}+e_{t}+\theta_{1} e_{t-1}+\theta_{2} e_{t-2}+\cdots+\theta_{s} e_{t-s}$

La parte de (AR) de ARIMA explica que la serie de tiempo retrocede sobre sus propios datos pasados. La parte (MA) de ARIMA revela que el error de pronóstico es una combinación lineal de errores pasados respectivos. La parte (I) de ARIMA muestra que los valores de los datos se han reemplazado con valores diferenciados de orden $(\mathrm{k})$ para obtener datos estacionarios (Ayala \& Bucio 2020).

La ecuación 1 muestra que los predictores son los puntos de datos (r) tardos para la sección autorregresiva y los errores (s) atrasados son para la parte de la media móvil, que son todos diferenciados. La predicción es la diferencia ( $\left.\mathrm{y}_{\mathrm{t}}{ }^{\prime}\right)$ en el k-ésimo orden. Esto se llama modelo ARIMA $(\mathrm{r}, \mathrm{k}, \mathrm{s})$. La estimación de los coeficientes $\sigma$ y $\theta$ para un $\mathrm{r}, \mathrm{k}, \mathrm{s}$ dado 
es el principio ARIMA cuando aprende de los datos de entrenamiento en una serie de tiempo (Tularam \& Saeed, 2016). Una vez que se especifica el modelo ARIMA con el valor de r, k, s, los coeficientes de la ecuación 1 compensan la estimación.

\section{Estimación del error porcentual absoluto medio de pronóstico, MAPE.}

Para una estimación simple de MAPE, en caso de que un valor observado (xi) es igual a cero, la función MAPE salta ese punto en el intervalo (Peña et al., 2019). El error porcentual absoluto medio MAPE, mesura la exactitud de ARIMA para la simulación ajustada de valores de serie de tiempo en el análisis cuantitativo de las variables. Es importante resaltar que las dos series de tiempo deben ser idénticas en tamaño, a su vez que este error es aplicado en el estudio como modelo no lineal (Gómez et al., 2015).

El error porcentual absoluto medio (MAPE) se escribe matemáticamente así:

$$
M A P E=\frac{100}{Z} \sum_{i=1}^{Z}\left|\frac{x i-x i *}{x i}\right|
$$

\section{Donde:}

xi, son las observaciones actuales de las series de tiempo

$\mathrm{xi}^{*}$, son las series de tiempo estimadas o pronosticadas

$\mathrm{Z}$, es el número de punto de datos no faltantes

De esta manera, se estimó el MAPE en cada una de las series. El error porcentual absoluto medio (MAPE) enuncia la exactitud como un porcentaje del error. Dado que el MAPE es un porcentaje, puede ser más comprensible que otros parámetros estadísticos de medición de exactitud. Por ejemplo, si el MAPE es 5, en promedio, la predicción está errada en un 5\% (Minitab, 2018; Barrionuevo, 2020).

Ampliando la gama de interpretación, si el valor de MAPE es inferior al 10\%, es una predicción de tipo (muy ajustado). Si el valor de MAPE está entre el 10\% y el 20\%, es una predicción de tipo (ajustado). Si el valor de MAPE está entre el 20 y el 50\%, es una predicción de tipo (moderadamente ajustado). Si el valor de MAPE es superior al 50\%, es un pronóstico (no ajustado) (Blanco \& Hancco, 2020).

\section{Algoritmo de aprendizaje de Kohonen}

Se plantea la estrategia de trazar un espacio n-dimensional usando una cadena unidimensional de unidades de Kohonen. Todas las unidades están ordenadas en sucesión de la forma $\mathrm{i}, \mathrm{j} . . . . . ., \mathrm{m}$. Cada unidad se convierte en la entrada n-dimensional (x) y calcula la excitación correspondiente. Los vectores de peso $n$-dimensionales $W_{i}, W_{j}, \ldots$, $\mathrm{W}_{\mathrm{m}}$ se utilizan para el cálculo iterativo, ver Figura 1. El proceso final de entrenamiento 
de la neurona artificial es la salida de code plots o mapas autoorganizados SOM, entonces cada unidad aprende a especializarse en diferentes regiones del espacio de entrada (Gámez et al., 2016). Cuando una entrada de tal región se alimenta a la red, la unidad correspondiente debe calcular la excitación máxima. En este sentido, el algoritmo de aprendizaje de Kohonen se emplea para validar este efecto. La red neuronal artificial RNA, sigue este modelo:

Figura 1. Una red unidimensional de unidades Kohonen

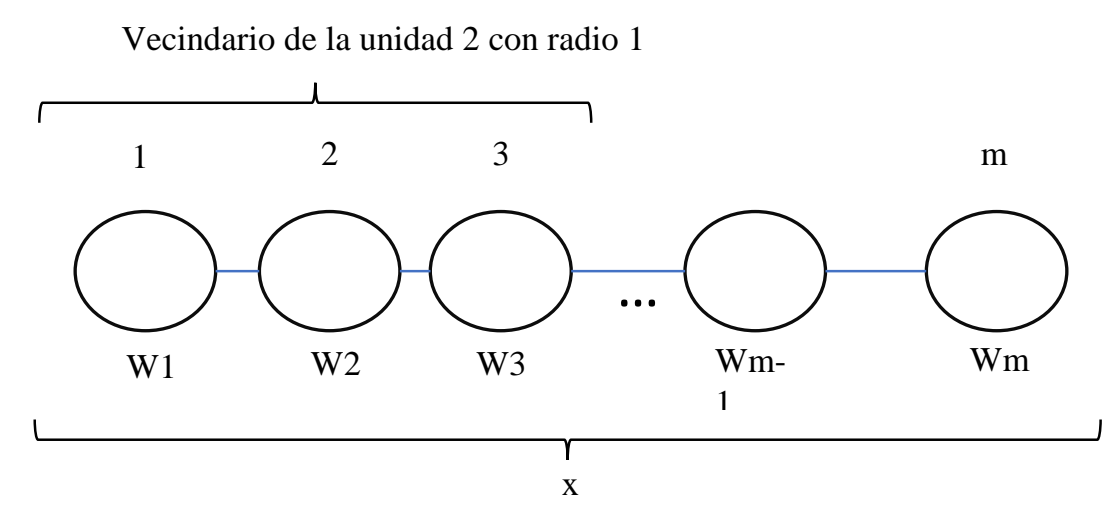

. Fuente: Elaboración propia

Una unidad de Kohonen estima la distancia euclidiana entre una entrada ( $\mathrm{x}$ ) y su vector de peso W. En la red unidimensional Kohonen, la vecindad de radio 1 de una unidad en la k-ésima posición consta de las unidades en las posiciones $\mathrm{k}-1$ y k+1 unidades en ambos extremos de la cadena tienen vecindarios asimétricos. La vecindad del radio (r) de la unidad $\mathrm{k}$ consta de todas las unidades ubicadas hasta $(\mathrm{r})$ posiciones desde $(\mathrm{k})$ hasta la izquierda o derecha de la cadena. Esto no es más que la segmentación del proceso de entrenamiento de la red, a partir del histórico de Producto Bruto Interno Trimestral por Tipo de Gasto 2007-2020-II con valores a precios constantes de 2007, para la república del Perú.

El aprendizaje o entrenamiento de Kohonen usa una función de vecindad $(\varphi)$, cuyo valor $\varphi(\mathrm{i}, \mathrm{k})$ representa la magnitud de asociación entre la unidad (i) y la unidad (k) durante el proceso de entrenamiento. Entonces, se define $\varphi(\mathrm{i}, \mathrm{k})=1$ para todas las unidades (i) en una vecindad del radio $(\mathrm{r})$ de la unidad $(\mathrm{k})$ y $\varphi(\mathrm{i}, \mathrm{k})=0$ para todas las demás unidades. El algoritmo de aprendizaje para las redes Kohonen es el siguiente:

Inicio: Los vectores de peso $\mathrm{n}$-dimensionales $\mathrm{W}_{\mathrm{i}}, \mathrm{W}_{\mathrm{j}}, \ldots, \mathrm{W}_{\mathrm{m}}$ de cálculo de las $(\mathrm{m})$ unidades, se seleccionan al azar. Un radio inicial (r), una constante de aprendizaje ( $\eta$ ) y una función de vecindad $(\varphi)$ son elegidas. 
- Paso 1: Se asigna un vector de entrada (c), aplicando la distribución de probabilidad esperada sobre el espacio de entrada.

- Paso 2: Se selecciona la unidad (k) con la máxima excitación, si y solo si la distancia entre $\mathrm{W}_{\mathrm{i}}$ y $\varepsilon$ es mínima, $\left.\mathrm{i}=1, \ldots, \mathrm{m}\right)$.

- Paso 3: Los vectores de peso W se reemplazan mediante la función de vecindad y la regla de reajuste, para $i=1, \ldots \ldots, \mathrm{m}$ :

$$
W_{i} \leftarrow W_{i}+\eta \varphi(i, k)\left(\varepsilon-W_{i}\right)
$$

- Final: Se detiene el proceso si y solo si el número máximo de iteraciones; tal que modifique $\eta$ y $\varphi$, según lo programado y se repite el Paso 1.

Las variaciones en los vectores de peso W en el Paso 3, los atraen en la dirección de la entrada $(\varepsilon)$. La iteración del proceso, distribuye uniformemente los vectores de peso en el espacio de entrada. Seguidamente, el radio del vecindario es reducido y; al actualizarse cada unidad, las unidades vecinas también se actualizan. Si el vector de peso $\mathrm{W}_{\mathrm{i}}, \mathrm{W}_{\mathrm{j}}, \ldots$, $\mathrm{W}_{\mathrm{m}}$ de una unidad es atraído por una región en el espacio de entrada, los vecinos también se sienten atraídos, aunque en menor valor. Para el proceso de aprendizaje, tanto el tamaño del vecindario como el valor de $(\varphi)$ disminuye gradualmente, de modo que la influencia de cada unidad sobre sus vecinos se reduce. La constante de aprendizaje registra la magnitud de las actualizaciones de peso y también se reduce gradualmente. El resultado esperado del aprendizaje de Kohonen es producir correcciones mayores en el inicio del algoritmo o entrenamiento que al final.

Para el caso de estudio, se establecieron los tiempos de presentación en 100. Esto corresponde al número de iteraciones que realizará el algoritmo de Kohonen. Se Seleccionó una topología hexagonal, esta implica que se organizarán 6 nodos en la vecindad directa de cada nodo. La función de vecindario es de tipo Gaussiano Toroidal. A continuación, se muestra la variación del PIB por tipo de gasto: 2007-2020 (Millones de soles), tomado de los cálculos base a precio constante de 2007 del Instituto Nacional de Estadística e Informática INEI, ver Tabla 1. 
Tabla 1. Volumen monetario del Producto Interno Bruto, Exportaciones e Importaciones trimestral, para el período 2007-2020 (Millones de soles 2007). Con información disponible al 15-08-2020 y actualizado con las cuentas nacionales anuales.

\begin{tabular}{cccc|cccc}
\hline Trimestre & PIB & Exportaciones & Importaciones & Trimestre & PIB & Exportaciones & Importaciones \\
\hline Mar-07 & 74,911 & 22,161 & 17,578 & Dic-13 & 117,759 & 30,856 & 32,569 \\
Jun-07 & 81,059 & 24,117 & 18,268 & Mar-14 & 113,291 & 27,273 & 31,715 \\
Set-07 & 79,962 & 26,507 & 20,522 & Jun-14 & 118,115 & 27,673 & 33,188 \\
Dic-07 & 83,761 & 27,989 & 20,889 & Set-14 & 116,258 & 28,536 & 33,258 \\
Mar-08 & 82,326 & 26,182 & 22,675 & Dic-14 & 119,644 & 29,332 & 32,586 \\
Jun-08 & 89,602 & 26,643 & 24,444 & Mar-15 & 115,554 & 27,171 & 31,898 \\
Set-08 & 87,670 & 28,054 & 25,633 & Jun-15 & 121,797 & 27,584 & 32,767 \\
Dic-08 & 89,272 & 27,737 & 23,804 & Set-15 & 119,969 & 30,145 & 33,859 \\
Mar-09 & 84,996 & 23,961 & 19,466 & Dic-15 & 125,186 & 32,722 & 33,494 \\
Jun-09 & 88,818 & 25,343 & 18,876 & Mar-16 & 120,581 & 28,211 & 31,994 \\
Set-09 & 87,944 & 26,579 & 20,521 & Jun-16 & 126,853 & 31,225 & 32,203 \\
Dic-09 & 90,935 & 29,157 & 22,302 & Set-16 & 125,173 & 34,985 & 35,035 \\
Mar-10 & 90,023 & 25,284 & 23,036 & Dic-16 & 128,974 & 37,022 & 34,857 \\
Jun-10 & 97,227 & 26,132 & 23,613 & Mar-17 & 123,173 & 32,664 & 33,106 \\
Set-10 & 95,850 & 27,975 & 27,761 & Jun-17 & 130,140 & 36,200 & 34,793 \\
Dic-10 & 98,981 & 29,044 & 28,329 & Set-17 & 128,714 & 37,189 & 37,352 \\
Mar-11 & 97,016 & 26,666 & 26,815 & Dic-17 & 132,188 & 36,966 & 38,357 \\
Jun-11 & 102,117 & 28,892 & 29,449 & Mar-18 & 127,044 & 34,714 & 35,521 \\
Set-11 & 102,090 & 29,586 & 30,266 & Jun-18 & 137,272 & 38,329 & 37,140 \\
Dic-11 & 105,033 & 29,243 & 30,177 & Set-18 & 131,877 & 37,762 & 37,410 \\
Mar-12 & 102,967 & 31,303 & 29,905 & Dic-18 & 138,472 & 37,810 & 38,226 \\
Jun-12 & 108,787 & 27,581 & 31,375 & Mar-19 & 130,130 & 35,080 & 35,700 \\
Set-12 & 108,678 & 29,810 & 34,274 & Jun-19 & 138,849 & 37,750 & 37,557 \\
Dic-12 & 110,767 & 29,246 & 32,821 & Set-19 & 136,153 & 37,781 & 38,682 \\
Mar-13 & 108,133 & 27,024 & 31,971 & Dic-19 & 141,029 & 38,717 & 38,262 \\
Jun-13 & 116,158 & 28,470 & 33,024 & Mar-20 & 125,604 & 32,922 & 33,793 \\
Set-13 & 114,385 & 30,925 & 34,491 & Jun-20 & 96,935 & 22,535 & 25,786 \\
\hline
\end{tabular}

Fuente: (Instituto Nacional de Estadística e Informática, 2020)

\section{RESULTADOS}

\section{Modelo optimizado ARIMA para el Producto Interno Bruto, con proyección a}

\section{Diciembre de 2022}

El valor final del AIC $(1108,606)$ supone un equilibrio entre reducir la complejidad y mantener un valor mínimo de desajuste entre el modelo teórico y estimado. En este caso, el mejor modelo para la serie temporal del PIB es ARIMA $(p, q, d)=(1,0,0)$; por lo que la serie de tiempo se retrocede sobre sus propios datos pasados. Este modelo se escogió por tener el menor AIC, ver Tabla 2. 
Tabla 2. Criterio de selección del mejor modelo ARIMA para el Producto Interno Bruto

\begin{tabular}{ccccc}
\hline $\mathrm{p}$ & $\mathrm{q}$ & $\mathrm{P}$ & $\mathrm{Q}$ & AICC \\
\hline 1 & 0 & 0 & 0 & 1108,606 \\
\hline
\end{tabular}

Fuente: elaboración propia

En la Tabla 3, el MAPE estima en 4,22 el porcentaje promedio del error de pronóstico por trimestre de adelanto en las Importaciones para el Perú, en promedio. Explicando que el pronóstico es acertado en una diferencia porcentual de 95,78\% es decir, entre la predicción al 2022 y los valores reales del período 2009-2020. Como el valor de MAPE es inferior al 10\%, es una predicción de tipo (muy ajustado). En este sentido, la optimización con ARIMA para la variable PIB, es el mejor modelo de predicción para el Perú. Además el cálculo del AIC $(1108,370)$ demuestra una aproximación válida, sabiendo que la muestra es grande, es el período por trimestre desde 2007. El valor del AICC $(1108,605)$ se asume en teoría para muestras finitas o pequeñas y; corrige el AIC en términos del número de trimestres de estudio. Entonces, si aumentamos cuatro trimestres más en la estimación del Producto Interno Bruto en millones de soles, se declara que el modelo identificado a partir de este criterio tiene un buen comportamiento respecto a la predicción ARIMA $(1,0,0)$.

Tabla 3. Resultados tras la optimización, estadísticos de bondad del ajuste para el PIB, durante el período 2007-2020, con proyección a diciembre de 2022

\begin{tabular}{lc}
\hline Observaciones & 54 \\
GL & 52 \\
MAPE(Dif) & 4,22 \\
MAPE & 4,22 \\
-2Log(Vero.) & 1104,370 \\
AIC & 1108,370 \\
AICC & 1108,605 \\
SBC & 1112,34 \\
Iteraciones & 21 \\
\hline \multicolumn{2}{c}{ Fuente: elaboración propia }
\end{tabular}

La tabla 4, muestra la autoregresión de primer orden, AR (1). Como el valor AR (1) $=0,998$ o 1,000 redondeado, entonces los efectos son permanentes, el modelo resultante es el paseo aleatorio. El error típico Hess es 0,003 y el modelo $(1,0,0)$ revela que la memoria es mayor con dependencia fuerte a cada trimestre pasado. Este es el comportamiento de la serie PIB de forma estacionaria hacia el año 2022. 
Tabla 4. Parámetros del modelo ARIMA (PIB), tras la optimización en el período 20072020, con proyección a diciembre de 2022

\begin{tabular}{cccccccc}
\hline $\begin{array}{c}\text { Pará } \\
\text { metro }\end{array}$ & Valor & $\begin{array}{c}\text { Error } \\
\text { típico } \\
\text { Hess. }\end{array}$ & $\begin{array}{c}\text { Límite } \\
\text { inferior } \\
\mathbf{( 9 5 \% )}\end{array}$ & $\begin{array}{c}\text { Límite } \\
\text { superior } \\
\mathbf{( 9 5 \% )}\end{array}$ & $\begin{array}{c}\text { Error } \\
\text { típico } \\
\text { asint. }\end{array}$ & $\begin{array}{c}\text { Límite } \\
\text { inferior } \\
(\mathbf{9 5 \%})\end{array}$ & $\begin{array}{c}\text { Límite } \\
\text { superior } \\
(\mathbf{9 5 \%})\end{array}$ \\
\hline $\mathrm{AR}(1)$ & 0,998 & 0,003 & 0,991 & 1,004 & 0,010 & 0,979 & 1,016 \\
\hline
\end{tabular}

Fuente: elaboración propia

El impacto de la pandemia del coronavirus en el crecimiento del PIB en Perú según datos de marzo y junio de 2020 con un valor en millones de soles de $(125,604)$ y $(96,935)$ respectivamente; evidencia una disminución en millones de soles de $(28,669)$ con efectos de proporción directa sobre los indicadores de importación y exportación del país. El pronóstico del modelo ARIMA $(1,0,0)$ para diciembre de 2020 es de $(96,451)$, pues la tendencia es a mantenerse en ese rango, de hecho el residuo estandarizado último de Junio 2020 es de $(-1,60)$, entonces el valor observado de PIB es menor que su valor estimado y por lo tanto se sobreestima la variable Producto Interno Bruto, Ver Tabla 5.

Para el primer trimestre de 2021 el valor del PIB pronóstico es de $(96,210)$ millones de soles, con tendencia a mantenerse. Sin embargo, para diciembre de 2021 la tendencia es a la baja, es decir, millones de soles $(95,491)$. Manteniéndose de esa forma hasta una caída a finales de 2022 en millones de soles $(94,540)$. El PIB es un indicador clave de la sanidad económica de Perú. Las variaciones porcentuales trimestrales del PIB muestran el ritmo de crecimiento del total de la economía.

Tabla 5. Predicciones y residuos para el Producto Interno Bruto, tras la optimización durante el período 2020-2020, con proyección a Diciembre de 2022

\begin{tabular}{|c|c|c|c|c|c|c|c|}
\hline Observ. & $\begin{array}{c}\text { Producto } \\
\text { Bruto } \\
\text { Interno }\end{array}$ & ARIMA(PIB) & Residuos & $\begin{array}{c}\text { Residuos } \\
\text { estandarizados }\end{array}$ & $\begin{array}{c}\text { Error } \\
\text { estándar }\end{array}$ & $\begin{array}{c}\text { Límite } \\
\text { inferior } \\
(95 \%)\end{array}$ & $\begin{array}{c}\text { Límite } \\
\text { superior } \\
(95 \%)\end{array}$ \\
\hline Mar-20 & 125,604 & 140,676 & $-15,072$ & $-0,85$ & & & \\
\hline Jun-20 & 96,935 & 125,290 & $-28,355$ & $-1,60$ & & & \\
\hline Set-20 & & 96,692 & & & 17,767 & 61,869 & 131,516 \\
\hline Dic-20 & & 96,451 & & & 25,095 & 47,264 & 145,637 \\
\hline Mar-21 & & 96,210 & & & 30,697 & 36,044 & 156,375 \\
\hline Jun-21 & & 95,970 & & & 35,402 & 26,583 & 165,356 \\
\hline Set-21 & & 95,730 & & & 39,531 & 18,250 & 173,210 \\
\hline Dic-21 & & 95,491 & & & 43,250 & 10,721 & 180,260 \\
\hline Mar-22 & & 95,252 & & & 46,657 & 3,804 & 186,700 \\
\hline Jun-22 & & 95,014 & & & 49,817 & $-2,625$ & 192,655 \\
\hline Set-22 & & 94,777 & & & 52,773 & $-8,657$ & 198,212 \\
\hline Dic-22 & & 94,540 & & & 55,559 & $-14,353$ & 203,435 \\
\hline
\end{tabular}

Fuente: elaboración propia 
En la figura 2, se muestra la evolución y predicción del volumen monetario o también denominado volumen de ventas para la variable Producto Interno Bruto, este es el comportamiento ARIMA $(1,0,0)$ e indica la caída del indicador entre Marzo de 2020 y Septiembre de 2020 a 96,692 millones de soles, la predicción es de tendencia a la baja para Septiembre de 2021 en 95,730 millones de soles y así hasta llega a finales de 2022 con un valor cotizado de 94,540 millones de soles.

Figura 2. Curva de predicción para el Producto Interno Bruto, tras la optimización en el período 2007-2020, con proyección a Diciembre de 2022

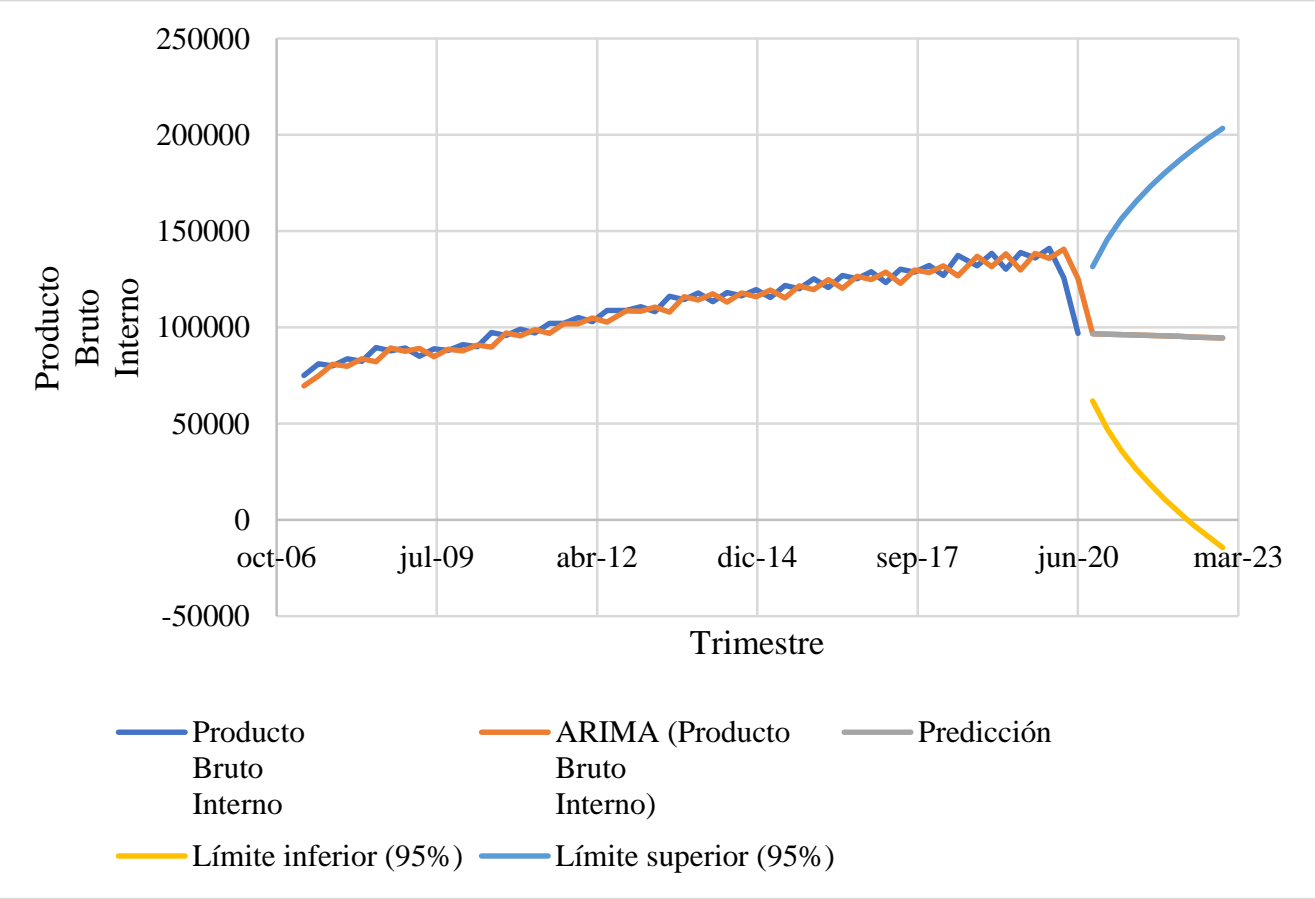

Fuente: elaboración propia

\section{Modelo optimizado ARIMA para las Exportaciones, con proyección a Diciembre de 2022}

El valor final del AIC $(1016,480)$ supone un equilibrio entre reducir la complejidad y mantener un valor mínimo de desajuste entre el modelo teórico y estimado. En este caso, el mejor modelo para la serie temporal de Exportaciones es $\operatorname{ARIMA}(p, q, d)=(1,0,0)$; por lo que la serie de tiempo se retrocede sobre sus propios datos pasados. Este modelo se escogió por tener el menor AIC, ver Tabla 6.

Tabla 6. Criterio de selección del mejor modelo ARIMA para las exportaciones

\begin{tabular}{ccccc}
\hline $\mathbf{p}$ & $\mathbf{q}$ & $\mathbf{P}$ & $\mathbf{Q}$ & AICC \\
\hline 1 & 0 & 0 & 0 & 1016,480 \\
\hline
\end{tabular}

Fuente: elaboración propia 
En la Tabla 7, el MAPE estima en 7,45 el porcentaje promedio del error de pronóstico por trimestre de adelanto en las Importaciones para el Perú, en promedio. Explicando que el pronóstico es acertado en una diferencia porcentual de $92,55 \%$ es decir, entre la predicción al 2022 y los valores reales del período 2009-2020. Como el valor de MAPE es inferior al 10\%, es una predicción de tipo (muy ajustado). En este sentido, la optimización con ARIMA para la variable Exportaciones, es el mejor modelo de predicción para el Perú. Además el cálculo del AIC $(1016,244)$ demuestra una aproximación válida, sabiendo que la muestra es grande, es el período por trimestre desde 2007. El valor del AICC $(1016,480)$ se asume en teoría para muestras finitas o pequeñas y; corrige el AIC en términos del número de trimestres de estudio. Entonces, si aumentamos cuatro trimestres más en la estimación de las Exportaciones en millones de soles, se declara que el modelo identificado a partir de este criterio tiene un buen comportamiento respecto a la predicción $\operatorname{ARIMA}(1,0,0)$.

Tabla 7. Resultados tras la optimización, estadísticos de bondad del ajuste para las exportaciones, durante el período 2007-2020, con proyección a Diciembre de 2022

\begin{tabular}{lc}
\hline Observaciones & 54 \\
GL & 52 \\
MAPE(Dif) & 7,45 \\
MAPE & 7,45 \\
-2Log(Vero.) & 1012,244 \\
AIC & 1016,244 \\
AICC & 1016,480 \\
SBC & 1020,222 \\
Iteraciones & 1 \\
\hline
\end{tabular}

Fuente: elaboración propia

La tabla 8, muestra la autoregresión de primer orden, $\operatorname{AR}(1)$. Como el valor $\operatorname{AR}(1)=0,994$ o 1,000 redondeado, entonces los efectos son permanentes, el modelo resultante es el paseo aleatorio. El error típico Hess es 0,007 y el modelo $(1,0,0)$ revela que la memoria es mayor con dependencia fuerte a cada trimestre pasado. Este es el comportamiento de la serie (Exportaciones) de forma estacionaria hacia el año 2022.

Tabla 8. Parámetros del modelo ARIMA (Exportaciones), tras la optimización en el período 2007-2020, con proyección a Diciembre de 2022

\begin{tabular}{cccccccc}
\hline $\begin{array}{c}\text { Pará } \\
\text { metro }\end{array}$ & Valor & $\begin{array}{c}\text { Error } \\
\text { típico } \\
\text { Hess. }\end{array}$ & $\begin{array}{c}\text { Límite } \\
\text { inferior } \\
\mathbf{( 9 5 \% )}\end{array}$ & $\begin{array}{c}\text { Límite } \\
\text { superior } \\
\mathbf{( 9 5 \% )}\end{array}$ & $\begin{array}{c}\text { Error } \\
\text { típico } \\
\text { asint. }\end{array}$ & $\begin{array}{c}\text { Límite } \\
\text { inferior } \\
\mathbf{( 9 5 \% )}\end{array}$ & $\begin{array}{c}\text { Límite } \\
\text { superior } \\
\mathbf{( 9 5 \% )}\end{array}$ \\
\hline $\mathrm{AR}(1)$ & 0,994 & 0,007 & 0,980 & 1,008 & 0,015 & 0,964 & 1,023 \\
\hline
\end{tabular}

Fuente: elaboración propia 
El impacto de la pandemia del coronavirus en el crecimiento de las Exportaciones en Perú según datos de marzo y junio de 2020 con un valor en millones de soles de $(32,922)$ y $(22,535)$ respectivamente; evidencia una disminución en millones de soles de $(10,387)$ como respuesta de proporción directa a la tasación del PIB. El pronóstico del modelo ARIMA (1, 0,0) para diciembre de 2020 es de (22,258), pues la tendencia es a mantenerse en ese rango, de hecho, el residuo estandarizado último de Junio 2020 es de $(-2,01)$, entonces el valor observado de las Exportaciones es menor que su valor estimado y por lo tanto se sobreestima a la variable, Ver Tabla 9.

Para el primer trimestre de 2021 el valor pronóstico de las exportaciones es de $(22,121)$ millones de soles, con tendencia a mantenerse. Sin embargo, para diciembre de 2021 la tendencia es a la baja, es decir, millones de soles $(21,715)$. Manteniéndose de esa forma hasta una caída a finales de 2022 en millones de soles $(21,184)$. Las exportaciones son dependientes de la variable explicativa del PIB. Por lo tanto, las variaciones porcentuales trimestrales del PIB muestran el ritmo de crecimiento de las exportaciones en el Perú.

Tabla 9. Predicciones y residuos para las exportaciones, tras la optimización durante el período 2020-2020, con proyección a diciembre de 2022

\begin{tabular}{lccccccc}
\hline Observ. & $\begin{array}{c}\text { Exportaci } \\
\text { ones }\end{array}$ & $\begin{array}{c}\text { ARIMA(Expo } \\
\text { rtaciones) }\end{array}$ & Residuos & $\begin{array}{c}\text { Resid. } \\
\text { estandarizados }\end{array}$ & $\begin{array}{c}\text { Error } \\
\text { estándar }\end{array}$ & $\begin{array}{c}\text { Límite } \\
\text { inferior } \\
(\mathbf{9 5 \%})\end{array}$ & $\begin{array}{c}\text { Límite } \\
\text { superior } \\
\text { (95\%) }\end{array}$ \\
Mar-20 & 32,922 & 38,478 & $-5,556$ & $-1,10$ & & & \\
Jun-20 & 22,535 & 32,719 & $-10,184$ & $-2,01$ & & & \\
Set-20 & & 22,396 & & & 5,067 & 12,463 & 32,328 \\
Dic-20 & 22,258 & & & 7,144 & 8,254 & 36,262 \\
Mar-21 & 22,121 & & & 8,723 & 5,022 & 39,219 \\
Jun-21 & 21,984 & & & 10,042 & 2,301 & 41,668 \\
Set-21 & 21,849 & & & 11,193 & $-0,089$ & 43,788 \\
Dic-21 & 21,715 & & & 12,224 & $-2,244$ & 45,674 \\
Mar-22 & 21,581 & & & 13,163 & $-4,219$ & 47,382 \\
Jun-22 & 21,448 & & & 14,030 & $-6,050$ & 48,946 \\
Set-22 & 21,316 & & & 14,836 & $-7,761$ & 50,394 \\
Dic-22 & 21,184 & & & 15,591 & $-9,373$ & 51,743 \\
\hline
\end{tabular}

Fuente: elaboración propia

En la figura 3, se muestra la evolución y predicción del volumen monetario o también denominado volumen de ventas para la variable Exportaciones, este es el comportamiento ARIMA $(1,0,0)$ e indica la caída del indicador entre Marzo de 2020 y Septiembre de 2020 a 22,396 millones de soles, la predicción es de tendencia a la baja para Septiembre de 2021 en 21,849 millones de soles y así hasta llega a finales de 2022 con un valor cotizado de 21,184 millones de soles. 
Figura 3. Curva de predicción para las exportaciones tras la optimización, en el período 2007-2020, con proyección a Diciembre de 2022

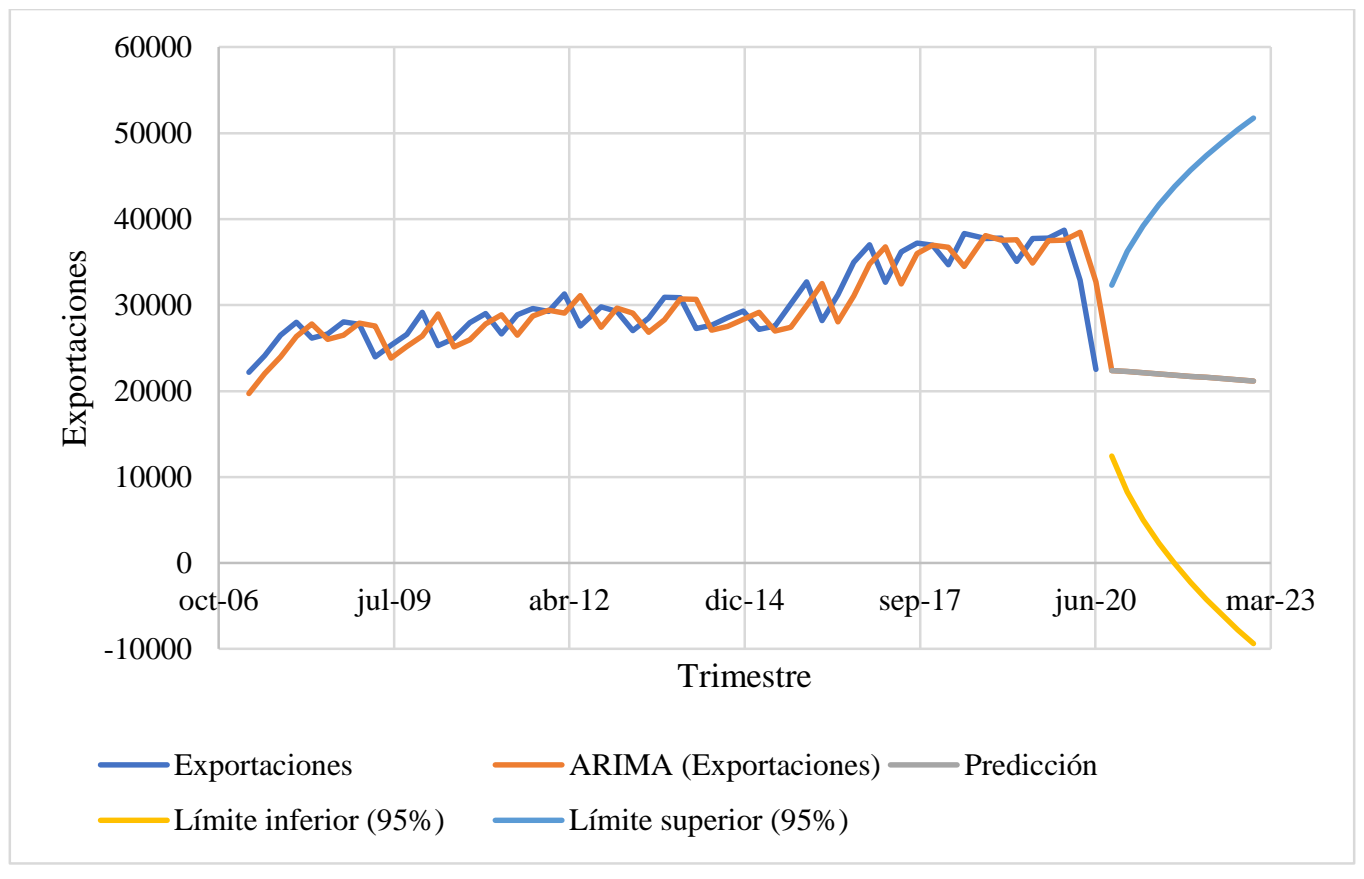

Fuente: elaboración propia

\section{Modelo optimizado ARIMA para las Importaciones, con proyección a Diciembre de 2022}

El valor final del AIC $(986,791)$ supone un equilibrio entre reducir la complejidad y mantener un valor mínimo de desajuste entre el modelo teórico y estimado. En este caso, el mejor modelo para la serie temporal de Importaciones es $\operatorname{ARIMA}(\mathrm{p}, \mathrm{q}, \mathrm{d})=(1,0,0)$; por lo que la serie de tiempo se retrocede sobre sus propios datos pasados. Este modelo se escogió por tener el menor AIC, ver Tabla 10.

Tabla 10. Criterio de selección del mejor modelo ARIMA para las importaciones

\begin{tabular}{ccccc}
\hline $\mathbf{p}$ & $\mathbf{q}$ & $\mathbf{P}$ & $\mathbf{Q}$ & AICC \\
\hline 1 & 0 & 0 & 0 & 986,791 \\
\hline
\end{tabular}

Fuente: elaboración propia

En la Tabla 11, el MAPE estima en 5,54 el porcentaje promedio del error de pronóstico por trimestre de adelanto en las Importaciones para el Perú, en promedio. Explicando que el pronóstico es acertado en una diferencia porcentual de 94,46\% es decir, entre la predicción al 2022 y los valores reales del período 2009-2020. Como el valor de MAPE es inferior al 10\%, es una predicción de tipo (muy ajustado). En este sentido, la optimización con ARIMA para la variable Importaciones, es el mejor modelo de predicción para el Perú. Además, el cálculo del AIC $(986,555)$ demuestra una aproximación válida, sabiendo que la muestra es grande, es el 
período por trimestre desde 2007. El valor del AICC $(986,790)$ se asume en teoría para muestras finitas o pequeñas y; corrige el AIC en términos del número de trimestres de estudio. Entonces, si aumentamos cuatro trimestres más en la estimación de las Importaciones en millones de soles, se declara que el modelo identificado a partir de este criterio tiene un buen comportamiento respecto a la predicción ARIMA $(1,0,0)$.

Tabla 11. Resultados tras la optimización, estadísticos de bondad del ajuste para las importaciones, durante el período 2007-2020, con proyección a Diciembre de 2022

\begin{tabular}{lc}
\hline Observaciones & 54 \\
GL & 52 \\
MAPE(Dif) & 5,54 \\
MAPE & 5,54 \\
-2Log(Vero.) & 982,555 \\
AIC & 986,555 \\
AICC & 986,790 \\
SBC & 990,533 \\
Iteraciones & 1 \\
\hline \multicolumn{2}{l}{ Fuente: elaboración propia }
\end{tabular}

La tabla 12, muestra la autoregresión de primer orden, AR(1). Como el valor $\mathrm{AR}(1)=0,996$ o 1,000 redondeado, entonces los efectos son permanentes, el modelo resultante es el paseo aleatorio. El error típico Hess es 0,005 y el modelo $(1,0,0)$ revela que la memoria es mayor con dependencia fuerte a cada trimestre pasado. Este es el comportamiento de la serie (Importaciones) de forma estacionaria hacia el año 2022.

Tabla 12. Parámetros del modelo ARIMA (Importaciones), tras la optimización en el período 2007-2020, con proyección a Diciembre de 2022

\begin{tabular}{cccccccc}
\hline Parámetro & Valor & $\begin{array}{c}\text { Error típico } \\
\text { Hess. }\end{array}$ & $\begin{array}{c}\text { Límite } \\
\text { inferior } \\
(95 \%)\end{array}$ & $\begin{array}{c}\text { Límite } \\
\text { superior } \\
(95 \%)\end{array}$ & $\begin{array}{c}\text { Error típico } \\
\text { asint. }\end{array}$ & $\begin{array}{c}\text { Límite } \\
\text { inferior } \\
(95 \%)\end{array}$ & $\begin{array}{c}\text { Límite } \\
\text { superior } \\
(95 \%)\end{array}$ \\
\hline AR(1) & 0,996 & 0,005 & 0,987 & 1,005 & 0,012 & 0,973 & 1,019 \\
\hline
\end{tabular}

\section{Fuente: elaboración propia}

El impacto de la pandemia del coronavirus en el crecimiento de las Importaciones en Perú según datos de marzo y junio de 2020 con un valor en millones de soles de $(33,793)$ y $(25,786)$ respectivamente; evidencia una disminución en millones de soles de $(8,007)$ como respuesta de proporción directa a la tasación del PIB. El pronóstico del modelo ARIMA $(1,0,0)$ para diciembre de 2020 es de $(25,591)$, pues la tendencia es a mantenerse en ese rango, de hecho el residuo estandarizado último de Junio 2020 es de $(-1,68)$, entonces el valor observado de las 
Importaciones es menor que su valor estimado y por lo tanto se sobreestima a la variable, Ver Tabla 13.

Para el primer trimestre de 2021 el valor pronóstico de las Importaciones es de $(25,494)$ millones de soles, con tendencia a mantenerse. Sin embargo, para diciembre de 2021 la tendencia es a la baja, es decir, millones de soles $(25,206)$. Manteniéndose de esa forma hasta una caída a finales de 2022 en millones de soles $(24,827)$. Las Importaciones son dependientes de la variable explicativa del PIB. Por lo tanto, las variaciones porcentuales trimestrales del PIB muestran el ritmo de crecimiento de las Importaciones en el Perú.

Tabla 13. Predicciones y residuos para las importaciones, tras la optimización durante el período 2020-2020, con proyección a diciembre de 2022

\begin{tabular}{rlcccccc}
\hline Observ. & Importaciones & $\begin{array}{c}\text { ARIMA } \\
\text { (Importac } \\
\text { iones) }\end{array}$ & Residuos & $\begin{array}{c}\text { Residuos } \\
\text { estandarizados }\end{array}$ & $\begin{array}{c}\text { Error } \\
\text { estándar }\end{array}$ & $\begin{array}{c}\text { Límite } \\
\text { inferior } \\
(\mathbf{9 5 \% )}\end{array}$ & $\begin{array}{c}\text { Límite } \\
\text { superior } \\
(\mathbf{9 5 \%})\end{array}$ \\
Mar-20 & 33,793 & 38,117 & $-4,324$ & $-0,92$ & & & \\
Jun-20 & 25,786 & 33,665 & $-7,879$ & $-1,68$ & & & \\
Set-20 & 25,688 & & & 4,702 & 16,472 & 34,904 \\
Dic-20 & 25,591 & & & 6,637 & 12,582 & 38,600 \\
Mar-21 & 25,494 & & & 8,113 & 9,592 & 41,396 \\
Jun-21 & 25,398 & & & 9,351 & 7,070 & 43,726 \\
Set-21 & 25,302 & & & 10,435 & 4,849 & 45,754 \\
Dic-21 & 25,206 & & & 11,409 & 2,844 & 47,569 \\
Mar-22 & 25,111 & & & 12,300 & 1,002 & 49,220 \\
Jun-22 & 25,016 & & & 13,125 & $-0,708.67$ & 50,741 \\
Set-22 & 24,921 & & & 13,895 & $-2,312$ & 52,156 \\
Dic-22 & 24,827 & & & 14,619 & $-3,826$ & 53,481 \\
\hline
\end{tabular}

Fuente: elaboración propia

En la figura 4, se muestra la evolución y predicción del volumen monetario o también denominado volumen de ventas para la variable Importaciones, este es el comportamiento ARIMA $(1,0,0)$ e indica la caída del indicador entre Marzo de 2020 y Septiembre de 2020 a 25,688 millones de soles, la predicción es de tendencia a la baja para Septiembre de 2021 en 25,302 millones de soles y así hasta llega a finales de 2022 con un valor cotizado de 24,827 millones de soles.

Figura: 14. Curva de evolución y predicción para las importaciones tras la optimización, en el período 2007-2020, con proyección a diciembre de 2022 


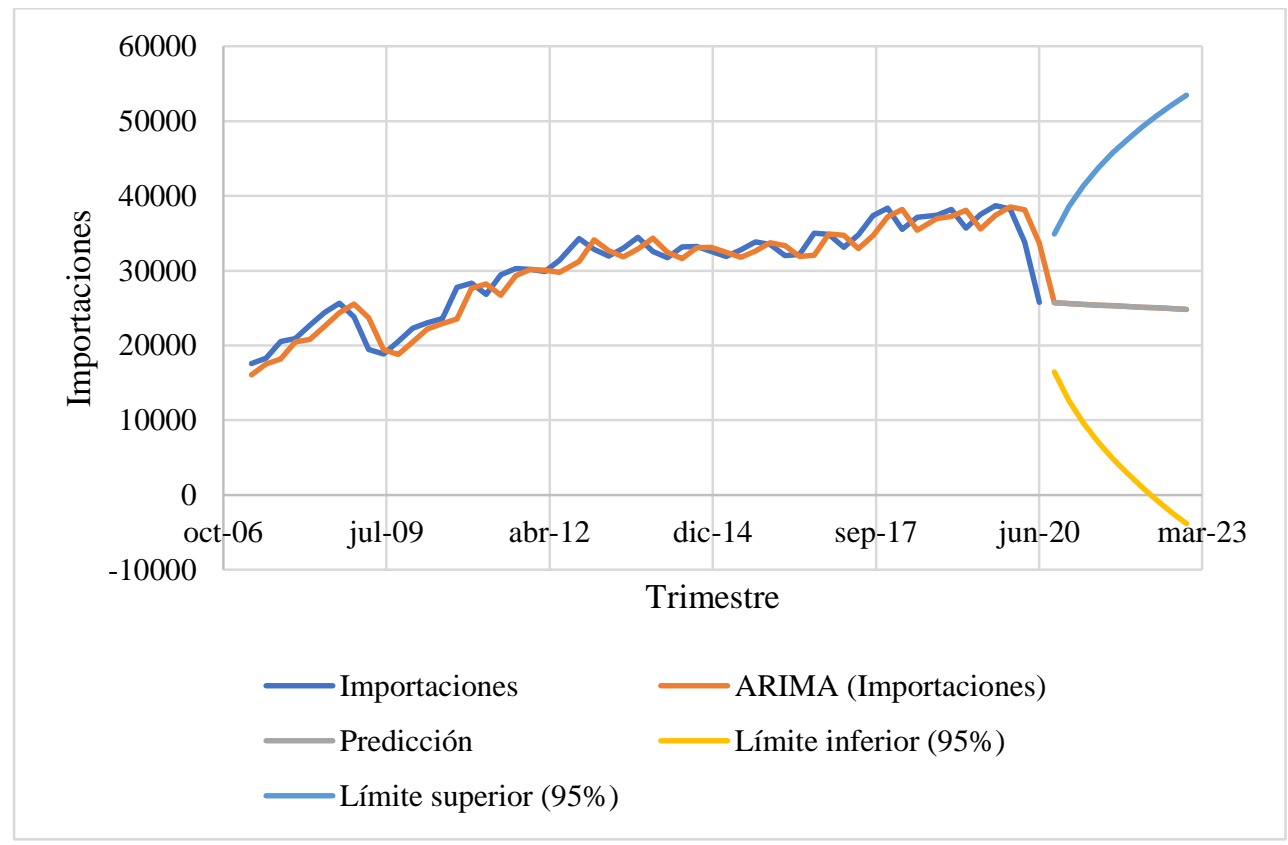

Fuente: elaboración propia

Al comparar los residuos estandarizados del PIB como variable explicativa de las Exportaciones e Importaciones, la variable más influenciada por el impacto del COVID-19 sobre el PIB, son las Exportaciones ya que en Junio de 2020 mostró el mayor valor con (-2,01). El análisis predictivo del modelo ARIMA $(1,0,0)$ estimó el MAPE del PIB en 4,22\%, Exportaciones 7,45\% e Importaciones 5,54\%, demostrando un ajuste significativo con el histórico 2007-2020 del INEI.

\section{Red Neuronal Artificial Kohonen (Self-Organizating Map, SOM)}

Se utilizó un aprendizaje no supervisado de tipo competitivo, donde una neurona de la capa de salida se activa ante la entrada, ajustándose los pesos de las conexiones en función de la neurona que ha resultado invicta, para la predicción en series de tiempo de la red (Gallardo Del Angel, 2020). Se evidencia los resultados de la clasificación de cada observación y el nodo o clase al que pertenece cada una de las distancias mínimas euclidianas, entre las variables: Producto Interno Bruto, Exportaciones e Importaciones, en base al histórico 2007-2020. El mayor peso de las observaciones recae en el nodo 6 de la Red Neuronal Artificial de Kohonen SOM con 23 patrones en común. Luego del entrenamiento, la red declara un pronóstico trimestral para el periodo 20202022 de 120,000 millones de soles en PIB, 32,000 millones de soles en exportaciones y 33,000 millones de soles en importaciones.

Seguidamente, el nodo 1 es el pronóstico más conservador con 18 patrones de repetición y simboliza una predicción trimestral de 102,500 millones de soles en PIB, 28,000 millones de soles en Exportaciones y 28,000 millones de soles en Importaciones; como resultado del entrenamiento de la Red. Mientras, el nodo 7 con cuatro repeticiones no evidencia patrones de comportamiento en común, ver Tabla 14. 
Tabla 14. Resultados de la clasificación Kohonen SOM, según la distancia euclidiana para una entrada $(x)$ y su vector de peso $W$

\begin{tabular}{ccc}
\hline Observaciones & Class & Distances \\
\hline 1 & 1 & 749953,637 \\
2 & 1 & 447961,703 \\
3 & 1 & 442873,744 \\
4 & 1 & 298263,292 \\
5 & 1 & 332190,320 \\
6 & 1 & 115313,734 \\
7 & 1 & 152110,388 \\
8 & 1 & 123717,299 \\
9 & 1 & 296777,323 \\
10 & 1 & 196671,553 \\
11 & 1 & 187557,005 \\
12 & 1 & 103521,966 \\
13 & 1 & 121817,882 \\
14 & 1 & 22587,205 \\
15 & 1 & 17363,631 \\
16 & 1 & 3579,669 \\
17 & 1 & 10777,697 \\
18 & 7 & 2451,050 \\
19 & 7 & 6005,475 \\
20 & 7 & 8273,555 \\
21 & 7 & 9854,413 \\
22 & 5 & 10238,034 \\
23 & 5 & 19079,614 \\
24 & 4 & 7424,326 \\
25 & 5 & 17464,685 \\
26 & 9 & 15715,458 \\
27 & 9 & 11979,997 \\
28 & 6 & 8038,728 \\
29 & 9 & 11490,314 \\
30 & 6 & 24228,472 \\
31 & 9 & 16911,894 \\
32 & 6 & 8459,233 \\
33 & 9 & 17140,663 \\
34 & 6 & 23224,465 \\
35 & 6 & 4438,932 \\
36 & 6 & 25091,129 \\
37 & 6 & 1680,5879 \\
38 & 6 & 45695,222 \\
39 & 6 & 36167,012 \\
40 & 6 & 103427,891 \\
41 & 6 & 8999,406 \\
42 & 6 & 117600,574 \\
43 & 6 & 115236,447 \\
44 & 6 & 193495,948 \\
45 & 6 & 58755,690 \\
46 & 6 & 344928,306 \\
47 & 6 & 185576,763 \\
48 & 6 & 390905,107
\end{tabular}




\begin{tabular}{ccc}
49 & 6 & 113280,181 \\
50 & 6 & 397814,684 \\
51 & 6 & 316132,875 \\
52 & 6 & 502274,280 \\
53 & 6 & 29976,143 \\
54 & 1 & 42060,134 \\
\hline
\end{tabular}

Fuente: elaboración propia

En la Figura 5, el progreso de entrenamiento muestra si el algoritmo SOM se ha estabilizado mediante iteraciones. En este caso, la línea de la red Kohonen SOM sigue en orden creciente hacia la derecha, entonces el SOM explica que es correcto el número de tiempos del histórico 2007-2020 tomados para el entrenamiento. Se realizaron 100 iteraciones, estimando la distancia media al vector de libro de códigos más cercano.

Por ejemplo, la línea va aumentando en la misma media de las iteraciones, hasta la 67. El entrenamiento de la Red Kohonen, estima el coeficiente de aprendizaje y simula un patrón de caída en el Producto Interno Bruto, Exportaciones e Importaciones en las iteraciones 68 y 69; es un efecto espejo al primer y segundo trimestre del 2020 por efecto de la pandemia COVID-19; luego continúa creciendo hasta alcanzar una distancia media al vector de libro de códigos más cercano, en términos de Producto Interno Bruto al final de cada período.

Figura 5. Progreso del entrenamiento de la Red Neuronal Artificial de Kohonen SOM, con topología Hexagonal y función vecindario Gaussiana-Toroidal para la segmentación del PIB 2007-2020 y proyección a Diciembre de 2022 


\section{Figura 5.}

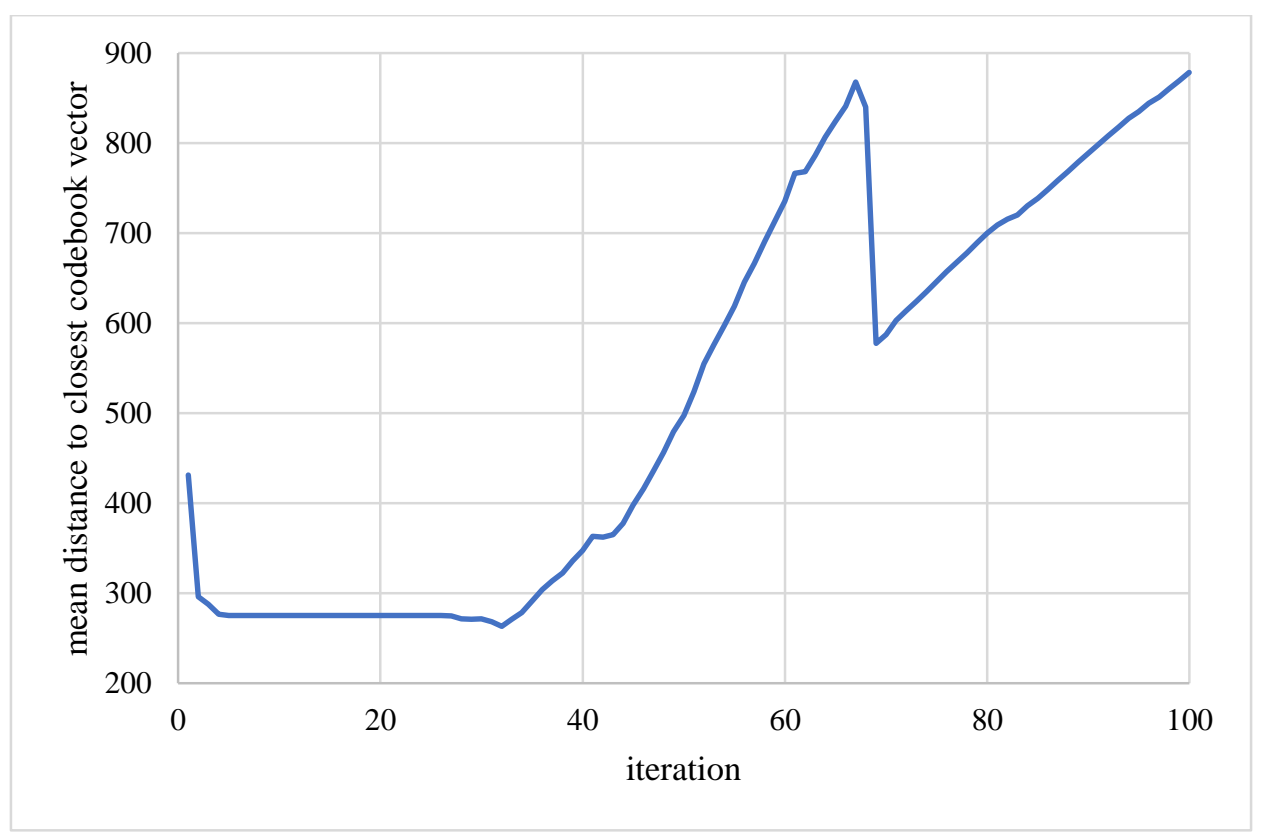

Fuente: elaboración propia

La Figura 6, manifiesta códigos de valores normalizados de cada variable dentro de cada nodo en forma de diagramas de abanico. En base al histórico del Producto Interno Bruto 2007-2020, el mejor pronóstico de la Red Kohonen SOM está en el nodo aumentado o vector de peso unidimensional 6 de izquierda a derecha, con una proyección por trimestre de 120,000 millones de soles en PIB, 32,000 millones de soles en Exportaciones y 33,000 millones de soles en importaciones. Sin embargo, hay 4 nodos con características similares para las tres variables, específicamente $\operatorname{los} \operatorname{nodos} 4,5,8$ y 9 de izquierda a derecha con predicciones de 110,000 millones de soles en PIB, 30,000 millones de soles en Exportaciones y 30,000 millones de soles en Importaciones. Mientras que el nodo 7 de color blanco no representan patrón alguno, el nodo 1 evidencia el mismo patrón de comportamiento para las 3 variables de estudio es decir, de dependencia lineal perfecta. Por ejemplo, el nodo 1 explica que el Producto Interno Bruto, Exportaciones e Importaciones se ubican en 102,500; 29,000 y 28,000 millones de soles respectivamente. Entonces, los nodos 1, 4, 5, 6, 8 y 9 explican el progreso del entrenamiento de la Red Neuronal Artificial de Kohonen SOM, con topología Hexagonal y función vecindario Gaussiana-Toroidal para la segmentación del PIB 2007-2020 y proyección a Diciembre de 2022 
Figura 6. Progreso del entrenamiento de la Red Neuronal Artificial de Kohonen SOM, con topología Hexagonal y función vecindario Gaussiana-Toroidal para la segmentación del PIB 2007-2020 y proyección a Diciembre de 2022

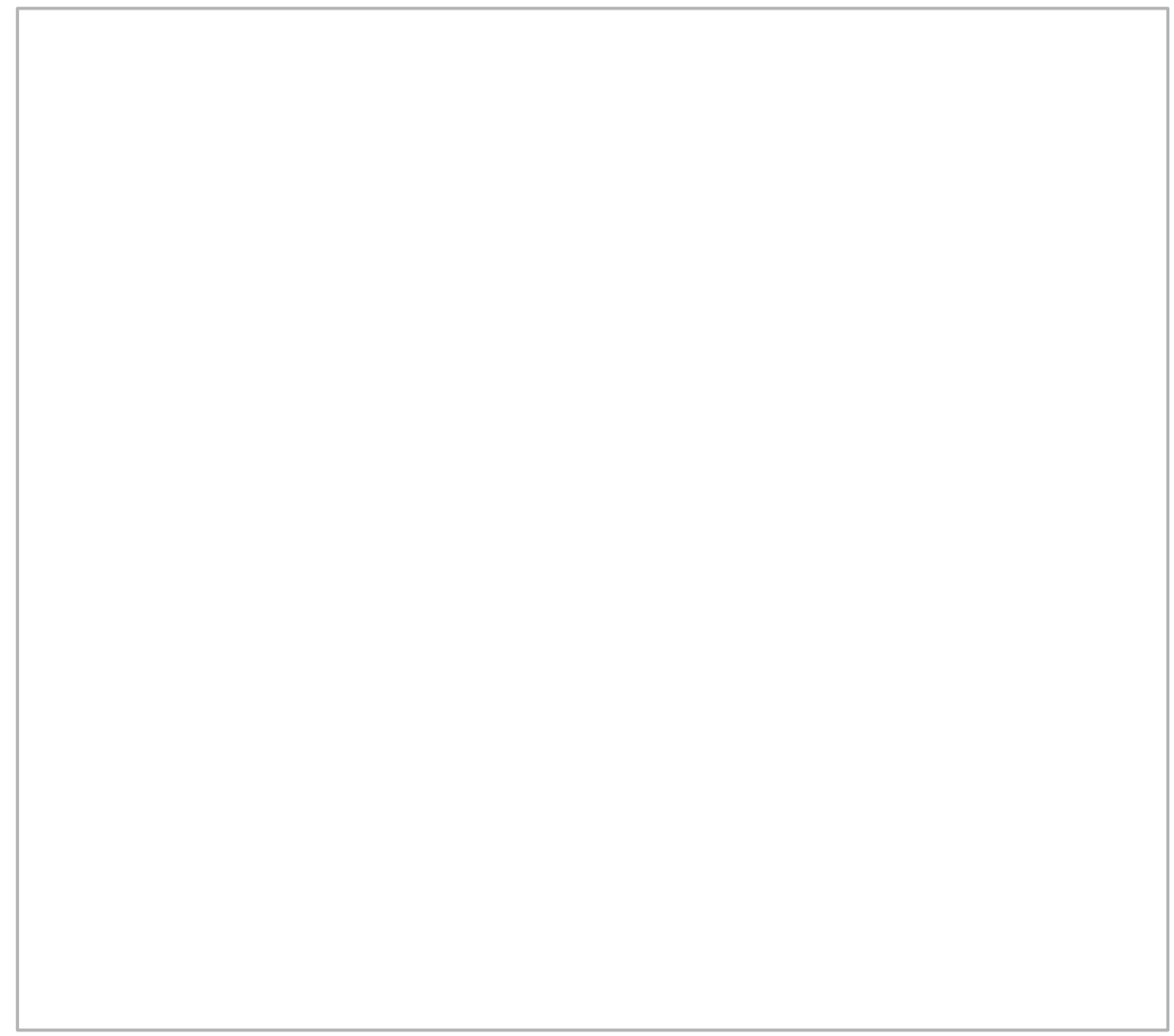

Fuente: elaboración propia

En la Figura 7, se muestra el número aproximado de observaciones implícitas en cada nodo. Por lo general, se necesita tener un gráfico de recuentos lo más homogéneo posible. Se puede observar que la variable Importación ha sido perfectamente discriminada respecto a las otras dos variables, quedando agrupados todos en la parte superior derecha del mapa, de color amarillo y rojo. Por su parte, las variables PIB y Exportaciones se reparten la parte superior izquierda, inferior izquierda e inferior derecha del mapa, respectivamente; compartiendo zonas adyacentes. Esto parece indicar que la variable Importación se diferencia de las otras, mientras que las variedades PIB y Exportaciones mantienen características más similares, aunque bien diferenciables. Las variables tienen en común, el número de observaciones en los nodos de mayor flujo en millones de soles, de color rojo. El mayor peso de las observaciones recae en un pronóstico de 120,000 millones de soles en Producto Interno Bruto, 32,000 millones de soles en Exportaciones y 33,000 millones en Importaciones, por trimestre para el período 2020-2022. 
Se explica la influencia de las variables: PIB, Exportaciones e Importaciones; exponiendo los valores normalizados dentro de cada nodo en el mapa. Para el nodo del Producto Interno Bruto, la red neuronal Kohonen SOM ajusta los valores medidos en disímiles escalas con afinidad a una escala común. El valor normalizado del PIB por trimestre para el período 2020-2022, está estimado en 110,000 millones de soles con tendencia a subir hasta 112,500 millones de soles y a la baja en un rango de 100,000 a 105,000 millones de soles.

La Probabilidad de llegar a un tope máximo PIB de 120,000 millones de soles por trimestre, estará influenciado por la entrada (x) con peso W a la red entrenada, correspondiente al valor del PIB de 125,604 millones de soles en el primer trimestre del 2020 a inicios de la pandemia del COVID-19, con un decrecimiento a 96,935 millones de soles para el segundo trimestre de 2020, dada la continuidad en las medidas de confinamiento por la emergencia sanitaria decretada por el Presidente de la República del Perú.

Para el nodo de las exportaciones en el periodo 2020-2022, se pronostica un flujo promedio de 30,000 millones de soles por trimestre, con tendencia a subir hasta 30,500 millones de soles y a la baja en un rango de 28,000 a 28,500 millones de soles. El valor máximo que se espera en las exportaciones es de 32,000 millones de soles por trimestre. La Red Neuronal Artificial Kohonen SOM predice a través del mapa de calor, una dependencia lineal perfecta entre el Producto Interno Bruto y las Exportaciones. Por ejemplo, si el PIB llegara a incrementarse desde el valor normalizado de 110,000 millones de soles hasta los 120,000 millones de soles; las Exportaciones van a variar desde 30,000 hasta 32,000 millones de soles.

En el caso de las Importaciones, el valor normalizado para cada trimestre en promedio se ubica en 30,000 millones de soles, con tendencia a subir hasta 31,000 millones de soles y a la baja en un rango de 27,000 a 28,000 millones de soles. El valor máximo que se espera en las exportaciones es de 33,000 millones de soles por trimestre.

En resumen, la RNA Kohonen SOM se ha entrenado de tal forma que, cada unidad aprendió a especializarse en diferentes regiones del espacio de entrada. En este sentido, por cada 20,000 millones de soles de variación en el PIB, la respuesta del nodo Exportaciones es 4,000 millones de soles y para Importaciones es de 6,000 millones de soles; este es el patrón de respuesta de la red. 
Figura 8. Gráfica de influencia de las variables: PIB, Exportaciones e Importaciones; normalizados dentro de cada nodo en el mapa, para el período 2020-2022.

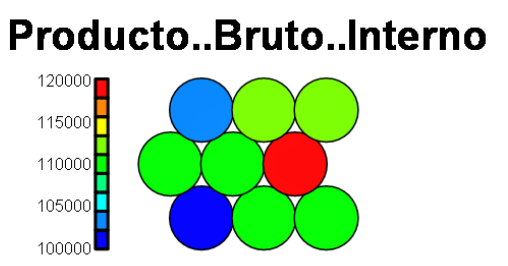

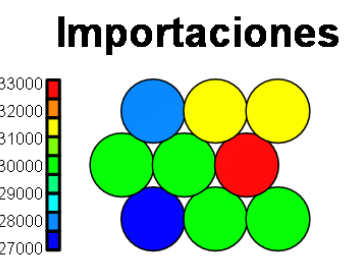

Fuente: elaboración propia

\section{CONCLUSIONES}

La República del Perú necesita del comercio para la evolución de la economía, medir las cuentas nacionales trimestrales, como parte exhaustiva del sistema de cuentas nacionales es fundamental. El éxito de un mayor volumen monetario del comercio interno y externo, contribuirá al impulso de exportaciones e importaciones, y que éstas tengan una mayor participación en el Producto Interno Bruto PIB (Organización Mundial del Comercio, 2019). La investigación actual cobra tal importancia si y solo si, el pronóstico del modelo espacio-temporal ARIMA para la estimación del Producto Interno Bruto y el volumen monetario de las Exportaciones e Importaciones para el período 2007-2022, es significativo con un error porcentual absoluto medio MAPE menor o igual 10. En este sentido, se estimó el MAPE del PIB en 4,22\%, Exportaciones 7,45\% e Importaciones 5,54\%, demostrando un ajuste significativo del pronóstico 2022 con el histórico 20072020 del INEI.

\section{Se confirma entonces la hipótesis de investigación y el modelo ARIMA explica:}

- Para el primer trimestre de 2021 el valor del PIB es de 96,210 millones de soles, en diciembre de 2021 la tendencia es a la baja, es decir, millones de soles 95,491. Manteniéndose de esa forma, hasta una caída a finales de 2022 en millones de soles 94,540 .

- Para el primer trimestre de 2021, el volumen monetario de las exportaciones es de 22,121 millones de soles, con tendencia a mantenerse, en diciembre de 2021 la tendencia es a la baja, es decir, millones de soles 21,715. Manteniéndose de esa forma hasta una caída a finales de 2022 en millones de soles 21,184. 
- Para el primer trimestre de 2021, el volumen monetario de las Importaciones es de 25,494 millones de soles, en diciembre de 2021 la tendencia es a la baja es decir, millones de soles 25,206. Manteniéndose de esa forma, hasta una caída a finales de 2022 en millones de soles 24,827 .

- Una vez cumplido el objetivo de investigación, se utilizó un aprendizaje no supervisado de tipo competitivo, donde una neurona de la capa de salida se activa ante la entrada, ajustándose los pesos de las conexiones en función de la neurona que ha resultado invicta. En resumen, la red neuronal de Kohonen SOM se ha entrenado de tal forma que, cada unidad aprendió a especializarse en diferentes regiones del espacio de entrada. En este sentido, por cada 20,000 millones de soles de variación en el PIB, la respuesta del nodo Exportaciones es 4,000 millones de soles y para Importaciones es de 6,000 millones de soles; este es el patrón de respuesta de la red y la finalización del estudio sobre la propuesta de un modelo espacio-temporal y red neuronal de Kohonen en la estimación del Producto Interno Bruto, Exportaciones e Importaciones para la república del Perú.

\section{REFERENCIAS BIBLIOGRÁFICAS}

Ayala Castrejón, R. \& Bucio Pacheco C. (2020). Modelo ARIMA aplicado al tipo de cambio peso-dólar en el periodo 2016-2017 mediante ventanas temporales deslizantes. Revista Mexicana de Economía y Finanzas Nueva Época, 15 (3), 331354. https://doi.org/10.21919/remef.v15i3.466

Barrionuevo, G. O. (2020). Predicción de propiedades mecánicas aplicando un sistema de inferencia neuro-difuso en manufactura aditiva. Universidad Ciencia Y Tecnología, 1(1), 81-88. Recuperado a partir de https://www.uctunexpo.autanabooks.com/index.php/uct/article/view/319

Blanco, Luis Francisco Laurente, \& Hancco, Ronald Wilson Machaca. (2020). Modeling and forecasting international tourism demand in Puno-Peru. Revista Brasileira de Pesquisa em Turismo, 14(1), 34-55. Epub March 23, 2020. https://doi.org/10.7784/rbtur.v14i1.1606

Ceballos Ramos, Leydis Marien, \& Rodríguez Flores, Leandro Alberto. (2020). Estrategia para el perfeccionamiento de la asignatura Elementos de Investigación Cualitativa en Salud. Revista de Ciencias Médicas de Pinar del Río, 24(2), 215-225. Epub 01 de marzo de 2020. Recuperado en 12 de septiembre de 2020, de 
http://scielo.sld.cu/scielo.php?script=sci_arttext\&pid=S1561-

$31942020000200215 \& \operatorname{lng}=\mathrm{es} \& \operatorname{tlng}=\mathrm{es}$

Gallardo Del Angel, Roberto. (2020). Financial time series forecasting using Artificial Neural Networks. Revista mexicana de economía y finanzas, 15(1), 105-122. Epub 03 de julio de 2020.https://doi.org/10.21919/remef.v15i1.376

Gámez Albán, Harol Mauricio, Orejuela Cabrera, Juan Pablo, Salas Achipiz, Óscar Ancízar, \& Bravo Bastidas, Juan José. (2016). Aplicación de mapas de kohonen para la priorización de zonas de mercado: Una aproximación práctica. Revista EIA, (25), 157-169. Retrieved October 19, 2020, from http://www.scielo.org.co/scielo.php?script=sci_arttext\&pid=S1794$12372016000100012 \& \operatorname{lng}=$ en\&tlng=es

Gauchi Risso, V. (2017). Estudio de los métodos de investigación y técnicas de recolección de datos utilizadas en bibliotecología y ciencia de la información. Revista $\begin{array}{llllll}\text { Española de } & \text { Documentación } & \text { Científica, } & 40 & \text { (2): } 175 .\end{array}$ http://dx.doi.org/10.3989/redc.2017.2.1333

Gómez Sarduy, J. R., Gregio di Santo, K., \& Saidel, M. (2015). Linear and non linear methods for prediction of peak load at University of Sao Paulo. Measurement, 78, 187-201. https://doi.org/10.1016/j.measurement.2015.09.053

Horna Zegarra, Indalecio Enrique. (2020). Perspectivas del financiamiento corporativo y el mercado de valores del Perú. RETOS. Revista de Ciencias de la Administración y Economía, 10(19), 135-152. https://dx.doi.org/10.17163/ret.n19.2020.08

https://www.inei.gob.pe/media/cide/convocatoria_2020.pdf

Instituto Nacional de Estadística e Información. (2020). Visible body: Segunda convocatoria nacional de investigaciones, 2020. Recuperado de https://www.inei.gob.pe/media/MenuRecursivo/boletines/bases-de-la-2daconvocatoria-nacional-de-investigaciones.pdf

Instituto Nacional de Estadística e Información. (2020). Visible body: convocatoria nacional de investigaciones, 2020. Recuperado de https://www.inei.gob.pe/estadisticas/indice-tematico/education/

Instituto Nacional de Estadística e Información. (9 de diciembre de 2019). INEI realiza curso taller internacional sobre "cuentas nacionales trimestrales por sectores institucionales". $\quad$ http://m.inei.gob.pe/prensa/noticias/inei-realiza-curso-taller- 
internacional-sobre-cuentas-nacionales-trimestrales-por-sectores-institucionales11970/\#: :text=Las\%20Cuentas\%20Nacionales\%20Trimestrales\%20por,constituy $\%$ C3\%A9ndose\%2C\%20por\%20tanto\%2C\%20en\%20una

International Finance Corporation. (2017). Análisis de datos y servicios financieros digitales. Recuperado de https://www.ifc.org/wps/wcm/connect/b8601e1d-baaa$4 \mathrm{cc} 4-\mathrm{b} 24 \mathrm{c}-$

7b7129c9e0f5/DATA+ANALYTICS+AND+DIGITAL+FINANCIAL+SERVICES +\%28SPANISH\%29.pdf?MOD=AJPERES\&CVID=m1bn. Yj

Minitab (2018). Interpretar todos los estadísticos y gráficas para Promedio móvil. https://support.minitab.com/es-mx/minitab/18/help-and-how-to/modelingstatistics/time-series/how-to/moving-average/interpret-the-results/all-statistics-andgraphs/\#mape

Organización Mundial del Comercio. (2 de abril de 2019). El crecimiento del comercio mundial pierde impulso en tanto que persisten las tensiones comerciales. https://www.wto.org/spanish/news_s/pres19_s/pr837_s.pdf

Peña Acción, Jesús Antonio, Viego Felipe, Percy Rafael, Gómez Sarduy, Julio Rafael, \& Padrón, Arturo Enrique. (2019). Pronóstico del consumo pico para la gestión energética de la Universidad de Cienfuegos. Revista Universidad y Sociedad, 11(4), 220-228. Epub 02 de septiembre de 2019. Recuperado en 19 de octubre de 2020, de http://scielo.sld.cu/scielo.php?script=sci_arttext\&pid=S221836202019000400220\&lng=es\&tlng=es

Song, H., Qiu, R. T. R., \& Park, J. (2019). A review of research on tourism demand forecasting. Annals of Tourism Research, 75, 338-362. https://doi.org/10.1016/J.ANNALS.2018.12.001

The World Bank. (2020). Graph, map and compare more than 1,000 time series indicators from the World Development Indicators. https://data.worldbank.org/country/PE Tularam, Anand, \& Saeed, Tareq. (2016). Oil-Price Forecasting Based on Various Univariate Time-Series Models. American Journal of OperationsResearch. 06. 226235. https://doi.org/10.4236/ajor.2016.63023 